\title{
Microbial EC50 Fold Change from Baseline
}

National Cancer Institute

\section{Source}

National Cancer Institute. Microbial EC50 Fold Change from Baseline. NCI Thesaurus.

Code C139114.

A fold change based on the concentration of a specific drug expected to produce 50 percent inhibition of population growth or replication of a microbial organism. 